\title{
EFFECT OF SELENIUM ON OXIDATIVE STRESS AND VIABILITY OF THE RAM SPERMATOZOA DURING THE SPERMATOGENESIS
}

\author{
M. Dolník' D. Mudroňová ${ }^{2}$, G. Lazarl, P. Mudron̆ ${ }^{1}$ \\ michal.dolnik890@gmail.com
}

${ }^{1}$ University of Veterinary Medicine and Pharmacy in Košice, Clinic of ruminants, Komenského 73, Košice, 04181, Slovak Republic

${ }^{2}$ University of Veterinary Medicine and Pharmacy in Košice, Institute of Immunology,

Komenského 73, Košice, 04181, Slovak Republic

The aim of the experiment was to determine the effect of a single subcutaneous application of Selevit inj. on the volume and density of ejaculates, sperm viability, level of oxidative stress (OS) and apoptosis in semen by using flow cytometry.

Ten rams were divided into two groups. The experimental group, $(E G ; n=6)$ was injected one time subcutaneously with the Selevit inj. at a dose of $5 \mathrm{ml}$ per animal (11 $\mathrm{mg}$ of sodium selenite). The control group, $(K ; n=4)$ was subcutaneously administered with physiological solution at a dose of $5 \mathrm{ml}$ per animal. Samples of blood and semen were collected from each ram prior to application of Se and at day one, 14, 26, 38, 50, 62 after selenium injection.

Results showed, Se concentration in the blood of EG was significantly higher, but short-term. Se concentration in the semen of the EG was significantly higher during the whole duration of the experiment (62 days). The level of OS was significantly reduced at day one, 14 and 60 after application of Selevit injection. The number of dead spermatozoa was significantly lower in the EG only at day 14 and 26 after Se application. There was only a slight increase in the percentage of sperm in the early phase of apoptosis in EG. There were no significant differences in ejaculate volume and sperm concentration between groups.

Single subcutaneous injection of Selevit is sufficient enough to maintain a significant long-term increase of Se concentration in semen and has a positive effect on the level of OS, but there was no substantial influence on the quality of ejaculates.

Keywords: SODIUM SELENITE, SPERMATOZOA, SPERMATOGENESIS, FLOW CYTOMETRY, RAMS

Mammalian spermatozoa have a large content of polyunsaturated fatty acids located in cytoplasmatic membranes, therefore they are highly susceptible to lipid peroxidation (LPO) caused by reactive oxygen species (ROS). The result of the ROS-induced damage is the disruption of sperm function and decreased semen quality [19]. Several defense mechanisms including antioxidants and antioxidant enzymes have been developed to prevent the LPO of sperm and maintain sperm motility and viability [21]. Many reports have suggested that selenium (Se) and vitamin E are important nutrients that act synergistically and can affect many biological processes including spermatogenesis and semen quality [12].

Se is an irreplaceable component of the antioxidant system as an integral part of glutathione peroxidase (GSH-Px). GSH-Px activity has been reported in the semen of several species including the dog, ram, human, rooster, buck and bull. If the
Se content in selenoproteins is low, it considerably decreases the possibility of fertilization [6].

Reduced sperm production and poor sperm quality, including impaired motility with flagella defects localized primarily in the midpiece, have been detected in Se-deficient animals [4]. Vitamin E was found to decrease the sperm abnormalities in the head of mice sperm and supplementation with Se and/or vitamin E improved the libido and semen characteristics in rams and bulls [7].

Spermatozoa are produced in the process of spermatogenesis. Spermatogenesis is the process of cell proliferation and differentiation from a spermatogonial stem cell to adult sperm. These complex transformations occur in seminiferous tubules of the mammalian testes and may proceed over an extended period of time, which is species specific [9]. Therefore, it is important to take into account the effect of an applied substance not only shortly after its application, but 
also during the course of the one cycle and after its ending what can last several weeks.

Most of the available works describe the positive effects of long-term supplementation with Se, with a preference for the organic form. However, information about the effect of single parenteral administration of the inorganic form of Se on male fertility is inadequate. For this reason, we have decided to test the effect of singel Se administraton on sperm fertility and Se concentration in spermatozoa and blood of rams with respect to the time course of the spermatogenic cycle.

\section{Materials and methods}

Ten adult rams aged 2-3 years and average body weight $63 \mathrm{~kg}$ were divided into two groups. The experimental group, $(\mathrm{EG} ; \mathrm{n}=6)$ was injected once subcutaneously with the Selevit inj. at a dose of $5 \mathrm{ml}$ per animal (11 $\mathrm{mg}$ of sodium selenite $-5 \mathrm{mg}$ of Se and $125 \mathrm{mg}$ of vitamin E per animal). The control group, $(\mathrm{C} ; \mathrm{n}=4)$ was subcutaneously administered only with saline at a dose of $5 \mathrm{ml}$ per animal.

Samples of blood were obtained via jugular puncture. Semen was collected by electroejaculation. Samples were collected before Selevit inj. application. and next collections were performed $1,14,26,38,50$, and 62 days post injection with respect to the course of spermatogenesis and the duration of the sperm passage through the epididymis.

Analysis. The concentration of selenium in the blood and the semen was determined using emission spectrometry with inductively coupled plasma on the optical emission spectrometer Opti$m a 2100 D V$ at the wavelength of $196.026 \mathrm{~nm}$. The samples were mineralized by wet digestion in microwave laboratory systems Milestone MLS 1200.

The semen was evaluated immediately after collection for: volume, concentration, live and dead counts, the level of apoptosis, and the level of oxidative stress (OS). Besides semen's volume other parameters were investigated by flow cytometry on a BD FACSCanto ${ }^{\mathrm{TM}}$ cytometer (Becton Dickinson Biosciences, USA) equipped with blue $(488 \mathrm{~nm})$ and red $(633 \mathrm{~nm})$ lasers and 6 fluorescence detectors. BD FACS Diva ${ }^{T M}$ software was used to analyze the obtained data.
Concentration of sperm was determined by counting beads, 123 count eBeads ${ }^{\mathrm{TM}}$ (eBioscience, ThermoFisher Scientific, USA). The numbers of sperms were expressed as $\log _{10}$ numbers $/ \mathrm{ml} \pm$ standard deviation. Sperm viability was determined by combined staining with propidium iodide (PI) and carboxyl fluorescein diacetate (cFDA). Apoptosis was evaluated with a commercial kit - FITC Annexin V Apoptosis Detection Kit (BD Pharmigen, USA). This kit contain a PI and Annexin-V labeled with FITC. Oxidative stress (OS) of the sperm cell membrane was assessed using the BODIPY C11 fluorescence dye according to Brouwers and Gadella (2003). In this assay, cells are stained with PI to distinguish living cells from damaged cells.

All results obtained from this experiment were statistically evaluated by two-way ANOVA with the supplementary Mann-Whitney test to compare treatment differences and Tukey's posthoc test to compare time differences.

\section{Results and discussion}

Se concentration in the blood of the experimental group (EG) was significantly higher $(\mathrm{P}<0.05)$ only 24 hours after Selevit injection. In the ejaculates of the EG there were significantly higher values of Se concentration than the control group (C) on day one and 14 (in both collections $\mathrm{P}<0.05$ ) after Se supplementation. Within the time dynamics, a significant increase of the Se concentration in EG was seen between the pre-injection collection and one day post-injection $(\mathrm{P}<0.05)$. There was no statistical difference between the experimental and control group in the volume and density of the ejaculates.

The higher values of oxidatively stressed sperms were found in the control animals. Significant differences between groups were reported on day 1 $(\mathrm{P}<0.05), 14(\mathrm{P}<0.05)$ and $62(\mathrm{P}<0.05)$. A significant decrease of oxidatively stressed sperm was observed in the EG between the pre-injection collection and $1^{\text {st }}$ day post-injection $(\mathrm{P}<0.001)$. Then, a gradual increase of OS was recognised in this group until day 50. Another significant decline $(\mathrm{P}<0.001)$ of the percentage of sperm damaged by oxidative stress was observed between days 50 and 62 .

The administration of selenium did not have a significant effect on the number of living 
and damaged sperm in the study. Statistically significant decrease of the percentage of dead sperm was observed in the EG on day 26 in comparison to the $\mathrm{C}(\mathrm{P}<0.05)$. The highest number of sperms in the early phase of apoptosis $(1-1.2 \%)$ was observed in the experimental group on day 38 . However, a significant effect was reported only on day 14. There were higher concentrations of living sperms $(\mathrm{P}<0.05)$ and significantly lower levels of dead sperms in the EG compared to the $\mathrm{C}(\mathrm{P}<0.05)$.

Many authors have presented the positive effect of selenium on the quality of ejaculate in many animal species [12]. However, some authors reported that the addition of an inorganic form of selenium to the feed did not improve the quality of ejaculates [3].

Our results showed, that the single dose of Selevit inj. caused an increase in Se concentrations in ejaculates of experimental rams in all samples. Increased concentrations of the Se in sperm were maintained for at least 62 days. It indicated a longterm supply of sperm by the testes. Therefore, we can conclude that the testes have an efficient mechanism for the use of Se to support spermatogenesis which is in accordance with [16]. According to [20], Se concentrations were higher in the reproductive apparatus (testes, sperm cells) than in other tissues and organs 23 days after intravenous administration of sodium selenite.

The highest values of Se concentrations in semen of the experimental versus control animals were recorded 24 hours after the administration of the Selevit inj., and subsequently at days 50 and 62 . [20] demonstrated that in the short period after Se administration, the Se concentration increased in seminal plasma, but no increase in Se in the sperm was observed. Therefore, we can conclude, that the increased Se concentration 24 hours after application was due to an excessive uptake of administered Se by the accessory glands. Additionally, low concentrations in the later collections suggests an inadequate incorporation of Se into sperm transported through the epididymis [15]. Antioxidative protection is ensured through GPX produced by the epithelium of the epididymis during the passage of sperm [14]. Increased concentrations of Se on days 50 and 62 after the Se injection, correspond with the increased incorporation of Se into sperm in the early stages of development, spermatogonia and primary spermatocytes. These conclusions are in accordance with findings of [2]. It has been demostrated that the testes exhibit fairly higher Se concentrations compared to other tissues and organs [1]. [5] also reported that testes of Se-deficient rats maintained Se concentration within normal levels, although its level in other organs declined significantly.

Our results are consistent with the results of [17], who reported no change in the volume and concentrations of ram sperm, even after long-term administration of sodium selenite. In contrast, our results are not consistent with the findings of [10], according to whome an increase of the volume and density of ejaculates and improvement of the sperm motility were observed after Se supplementation.

A significant effect on the viability of sperm in rams supplemented by Se was detected only on day 26 , when a significant decrease of dead sperm was observed compared to the control animals. However, there was no increase in the number of living sperm. Similarly, authors [17] and [8] have not reported a significant influence on the number of living and dead sperm after supplementation with both organic and inorganic Se. On the contrary, other authors demonstrated increase of sperm viability after application of Se or combination of Se and vitamin E [7, 12]. The positive effect of Se on sperm viability was also demonstrated in vitro [6].

Significant increase of the Se concentrations and a decrease of OS were observed in the EG in most collections compared to day before application of Selevit inj. The analyses of first two ejaculate samples indicate the selenium antioxidant protection in seminal plasma and the epididymis secretions. This is consistent with the results of [18], according to which Se is not incorporated by adult sperm. The results of day 62 point to the incorporation of Se in the early stages of sperm development and the subsequent positive influence on the OS level in the samples. However, improvement of sperm viability was not observed. According to [11] application of Se improves the antioxidant properties of seminal plasma by increasing the activity of antioxidant enzymes and reducing the level of lipoperoxidation. [13] found high levels of reactive oxygen species in infertile 
patients as well as a greater level of apoptosis compared to healthy subjects. We observed a non-significant increase in sperm in the early phase of apoptosis in EG during the study.

\section{Conclusion}

Based on our results, we can assume that a single subcutaneous injection of Selevit inj. is not sufficient to maintain higher levels of blood selenium for longer period. Although there was a long-term increase of selenium concentration in semen and a positive effect on the level of oxidative stress, no significant effect on the quality of ejaculates was observed after a single injection of Selevit inj. Based on the number of available studies, as well as our results, it can be concluded that the final concentration of selenium in the testes and its effect on the quality of the ejaculate, may depend on the form of the administered selenium, the method of administration and the duration of selenium supplementation.

1. Ahsan U., Kamran Z., Raza I., Ahmad S., Babar W., Riaz M. H., Iqbal Z. Role of selenium in male reproduction - a review. Animal Reproduction Science, 2014, vol. 146, issue 1-2, pp. 55-62. DOI: 10.1016/j.anireprosci.2014.01.009.

2. Alabi S. N., Beilstein M. A., Whanger P. D. Chemical forms of selenium presentin rat and ram spermatozoa. Biological Trace Element Research, 2000, vol. 76, issue 2, pp. 161-173. DOI: 10.1385/ BTER:76:2:161.

3. Audet J., Laforest J. P., Martineau G. P., Matte J. J. Effect of vitamin supplements on some aspect of performance, vitamin status, and semen quality in boars. Journal of Animal Science, 2004, vol. 82, issue 2, pp. 626-633. DOI: 10.1093/ansci/82.2.626.

4. Beckett J. G., Arthur R. J. Selenium and endocrine systems. Journal of Endocrinology, 2005, vol. 184 , issue 3 , pp. 455-465. DOI: 10.1677/ joe.1.05971.

5. Behne D., Höfer T.,Berswordt-Wallrabe von R., Elger W. Selenium in the testis of the rat: studies on its regulation and its importance for the organism. The Journal of Nutrition, 1982, vol. 112, issue 9, pp. 1682-1687. DOI: 10.1093/jn/112.9.1682.

6. Dorostkar K., Alavi-Shoushtari M. S., Mokarizadeh A. Effects of in vitro selenium addition to the semen extender on the spermatozoa characteristics before and after freezing in water buffaloes (Bubalus bubalis). Veterinary Research Forum, 2012, vol. 3, issue 4, pp. 263-268.

7. El-Sheshtawy R. I.,Ahmed W. M., Zaabal M. M., Ali G. A., Shalaby S. I. Effect of selenium and/or vita- min $\mathrm{E}$ administration on semen characteristics, plasma testosterone level and some immunogenetic constituents in seminal plasma proteins of Baladi bucks. Global Veterinaria, 2014, vol. 12, issue 6, pp. 878-884. DOI: 10.5829/idosi.gv.2014.12.06.9478.

8. Ghorbani A., Moeini M. M., Souri M., Hajarian $\mathrm{H}$. Influences of dietary selenium, zinc and their combination on semen characteristics and testosterone concentration in mature rams during breeding season. Journal of Applied Animal Research, 2018, vol. 46, issue 1, pp. 813-819. DOI: 10.1080/09712119.2017.1406858.

9. Hopper M. R. Bovine reproduction. John Wiley \& Sons Inc., 2015, 800 p. DOI: 10.1002/9781118833971.

10. Kistanova E., Metodiev N., Raycheva E., Abadjieva D., Stefanov R., Mladenova V., Blazhev B., Nevitov M., Boryaev G. The effect of injective application of selenopyran on the prolonged increase of the selenium content in blood and sperm of rams. Biotechnology in Animal Husbandry, 2015, vol. 31, issue 4, pp. 481-489. DOI: 10.2298/BAH1504481K.

11. Kumar P., Yadav B., Yadav S. Effect of zinc and selenium supplementation on antioxidative status of seminal plasma and testosterone, $\mathrm{T}_{4}$ and $\mathrm{T}_{3}$ level in goatbloodserum. Journal of Applied Animal Research, 2013, vol. 41, issue 4, pp. 382-386. DOI: 10.1080/09712119.2013.783482.

12. Mahmoud G. B., Abdel-Raheem S. M., Hussein H. A. Effect of combination of vitamin $E$ and selenium injections on reproductive performance and blood parameters of Ossimi rams. Small Ruminant Research, 2013, vol. 113, issue 1, pp. 103-108. DOI: 10.1016/j. smallrumres.2012.12.006.

13. Moustafa M. H., Sharma R. K., Thornton J., Mascha E., Abdel-Hafez M. A., Thomas A. J., Agarwal A. Relationship between ROS production, apoptosis and DNA denaturation in spermatozoa from patient sexamined for infertility. Human Reproduction, 2004, vol. 19, issue 1, 129-138. DOI: 10.1093/humrep/deh024.

14. Noblanc A., Kocer A., Chabory E., Vernet P., Saez F., Cadet R., Conrad M., Drevet J. R. Glutathione peroxidases at work on epididymal spermatozoa: an example of the dual effect of reactive oxygen species on mammalian male fertilizing ability. Journal of Androlory, 2011, vol. 32, issue 6, pp. 641-650. DOI: 10.2164 /jandrol.110.012823.

15. Olson G. E., Winfrey V. P., Hill K. E., Burk R. F. Sequential development of flagellar defects in spermatids and epididymal spermatozoa of selenium-deficient rats. Reproduction, 2004, vol. 127, issue 3, pp. 335-342. DOI: $10.1530 /$ rep. 1.00103 .

16. Olson G. E., Winfrey V. P., NagDas S. K., Hill K. E., Burk R. F. Selenoprotein P is required for mouse sperm development. Biology of Reproduction, 2005, vol. 73, issue 1, pp. 201-211. DOI: 10.1095/ biolreprod.105.040360.

17. Piagentini M., Silva D. C., Dell'Aqua C. P. F., Moya-Araujo C. F., Codognoto V. M., Ramos A. A., 
Oba E. Effect of selenium supplementation on semen characteristics of Brazil's rams. Reproduction in Domestic Animals, 2017, vol. 52, issue 3, pp. 355-358. DOI: $10.1111 /$ rda.12903.

18. Pond F. R., Tripp M. J., Wu A. S. H., Whanger P. D., Schimtz J. A.Incorporation of selenium-75 into semen and reproductive tissues of bulls and rams. Reproduction, 1983, vol. 69, issue 2, pp. 411-418. DOI: 10.1530/jrf.0.0690411.

19. Shi L., Yang R., Yue W., Xun W., Zhang C., Ren Y., Shi L, Lei F. Effect of nano-selenium on semen quality, glutathione peroxidase activity and testis ultrastructure in male Boer goats. Animal Reproduc- tion Science, 2010, vol. 118, issue 2-4, pp. 248-254. DOI: $10.1016 /$ j.anireprosci.2009.10.003.

20. Smith D. G., Senger P. L., McCutchan J. F., Landa C. A. Selenium and glutathione peroxidase distribution in bovine semen and selenium- 75 retention by the tissues of the reproductive tract in the bull. Biology of Reproduction, 1979, vol. 20, issue 2, pp. 377-383. DOI: 10.1095/biolreprod20.2.377.

21.Zubair M. S.,Ali M.A. R.,Ahmad M., Sajid S. M., Ahmad I., Gul S. T. Effect of selenium and vitamin E on cryopreservation of semen and reproductive performance of animals. Journal of Entomology and Zoology Studies, 2015, vol. 3, issue 1, pp. 82-86. 